Volume 9, No.4, July - August 2020

International Journal of Advanced Trends in Computer Science and Engineering

Available Online at http://www.warse.org/IJATCSE/static/pdf/file/ijatcse270942020.pdf

https://doi.org/10.30534/ijatcse/2020/270942020

\title{
ComicMart: Digital Comic Aggregator Platform with Monetization Schemes for Local Artists
}

\author{
Ng Zhen Hao ${ }^{1}$, Raja Rina Raja Ikram², Nor Mas Aina Md Bohari ${ }^{3}$, Hea Choon $\mathrm{Ngo}^{4}$, \\ Lizawati Salahuddin ${ }^{5}$, Nor Hafeizah Hassan ${ }^{6}$ \\ ${ }^{1}$ Centre for Advanced Computing Technology (C-ACT), Fakulti Teknologi Maklumat dan Komunikasi, \\ Universiti Teknikal Malaysia Melaka, b031710151@ student.utem.edu.my \\ ${ }^{2}$ Centre for Advanced Computing Technology (C-ACT), Fakulti Teknologi Maklumat dan Komunikasi, \\ Universiti Teknikal Malaysia Melaka, raja.rina@utem.edu.my \\ ${ }^{3}$ Centre for Advanced Computing Technology (C-ACT), Fakulti Teknologi Maklumat dan Komunikasi, \\ Universiti Teknikal Malaysia Melaka, aina@utem.edu.my \\ ${ }^{4}$ Centre for Advanced Computing Technology (C-ACT), Fakulti Teknologi Maklumat dan Komunikasi, \\ Universiti Teknikal Malaysia Melaka, heachoon@utem.edu.my \\ ${ }^{5}$ Centre for Advanced Computing Technology (C-ACT), Fakulti Teknologi Maklumat dan Komunikasi, \\ Universiti Teknikal Malaysia Melaka, lizawati@utem.edu.my \\ ${ }^{6}$ Centre for Advanced Computing Technology (C-ACT), Fakulti Teknologi Maklumat dan Komunikasi, \\ Universiti Teknikal Malaysia Melaka, nor_hafeizah@utem.edu.my
}

\begin{abstract}
This paper proposes ComicMart, a system that provides digital alternative to comic publisher who usually sells their work in physical form. Methodology used in the study was survey through convenience sampling. Requirements elicitation was conducted using surveys. Questionnaires were distributed to comic hobbyists and enthusiasts to collect feedback and opinion on the current implementation and proposed design. The study done shows that out of 53 respondents, the perceived rate of users who thought that printed comic books are getting expensive was $77.3 \%$. A design of ComicMart was then proposed from the respondents' feedback. Finally, an implementation prototype was developed. Most of the comic enthusiasts believed that comic books in the form of print media is getting too costly and not affordable. However, by selling the digital version of the comics, the price can be reduced, and people could afford them to buy them. The proposed project is supposed to replace physical comic bookstores with digital distribution medium. Freelancer artists who wish to promote themselves also can upload their works to the website and make it free-to-read for everyone.
\end{abstract}

Key words: Digital comics, e-books, web-application

\section{INTRODUCTION}

Comic Mart provides digital alternative to comic publisher who usually sells their work in physical form. More often than not, the price of the books is expensive and not many people will buy them [1]. However, by selling the digital version of the comics, the price can be reduced and people could afford them to buy them [2]. The proposed project will develop a web application to access the comics. The comics and their metadata will be stored in the server [23]. Publishers or freelancer artists are able to upload their works here by signing up for a free account. A fixed percentage of the earnings will be given to the developers if the profit gained by the publisher exceeds a certain threshold. This is to promote talented artists to upload their fan-made comics to the website.

The proposed project is supposed to replace physical comic book stores with digital distribution medium. Physical comic books are often expensive and not many people buy them [3]. With distributing digital editions of their comics, the publisher can reduce their price to be affordable and hence attracting comic readers to pay to support the publisher[19]. Freelancer artists who wish to promote themselves also can upload their works to the website and make it free-to-read for everyone.

\section{BACKGROUND}

Comic books have become a form of printed media that appears in all genres of literature for youth [4]. Graphics novels known as comics are popular among young generations who grow up in visual environment [5]. Being able to print and publish comic books is a huge investment and requires a lot of money. As a result, one must go through a publisher to be able to monetize their work. On the other hand, a publisher can only publish limited number of books because printing physical books is expensive [20]. This is 
Ng Zhen Hao et al., International Journal of Advanced Trends in Computer Science and Engineering, 9(4), July - August 2020,6024 - 6030

negatively affecting the comic industry and hurting the young comic artists. Many talented young artists could go unnoticed.

There is also a lack of platform for local artists to publish their work online. Therefore, it is hard for local artists to monetize their work without going through a publisher [6]. Also, it gives no support to creators to further create new content [7][22]. A lot of time and energy also has been depleted to transform printed media to digital format so far [8].

This system is about combining traditional comic store with the e-wallet ( $\mathrm{PayPal})$ functionality. The users can experience the advantage and fluid process of consuming comic books which are bought from online bookstore without going out of home [9]. The system offers the general functions of comic reader in the form of web application. The system also allows artists to upload their works and dictate price for it. Consumers who are interested can then pay for the locked chapters using points from e-wallet.

\section{RELATED WORKS}

Table 1 shows the comparison between the existing comic aggregators/applications and proposed application. Based on Table 1, there are 4 items listed. They are some of the most used comic aggregator platform in Malaysia. MangaDex supports comic uploading and has its own digital reader, but it does not provide a monetization scheme. This means the artists are forced to provide their work for free.

Table 1: Comparison between the existing comic aggregators/applications and proposed application

\begin{tabular}{l|c|c|c|c|}
\hline System/Features & $\begin{array}{l}\text { Can } \\
\text { upload } \\
\text { e-comic }\end{array}$ & $\begin{array}{l}\text { Has } \\
\text { digital } \\
\text { reader }\end{array}$ & $\begin{array}{l}\text { Has } \\
\text { monetization }\end{array}$ & $\begin{array}{l}\text { Localized } \\
\text { for } \\
\text { Malaysia }\end{array}$ \\
\hline & $\sqrt{ }$ & $\sqrt{ }$ & & \\
\hline WebToons & $\sqrt{ }$ & $\sqrt{ }$ & $\sqrt{ }$ & \\
\hline Gempak Starz & & $\sqrt{ }$ & $\sqrt{ }$ & $\sqrt{ }$ \\
\hline $\begin{array}{l}\text { ComicMart } \\
\text { (Proposed } \\
\text { application) }\end{array}$ & $\sqrt{ }$ & $\sqrt{ }$ & $\sqrt{ }$ & $\sqrt{ }$ \\
\cline { 2 - 5 } & & & &
\end{tabular}

WebToons on the other hand, supports uploading comics, has digital reader and monetization schemes. Unfortunately, it is not localized for Malaysia and the type of content is not aligned with the Malaysia's artists work

Gempak Starz is the largest comic vendor in Malaysia. It is localized to fit Malaysia's taste. It has monetization scheme and its own digital store to sell comics. However, the store only contains digital copies of the already printed books. It does not support uploading comic books by random people.

ComicMart is proposed to tackle the problem faced by local artists nowadays is that they have to go through publisher to monetize their work. It is also more unlikely to occur because physical books are expensive to make and publishers can only pick a few. This limits the creativity of local artists. By providing a digital platform for free, it is hoped that the local comic scene can be expanded.

\section{METHODOLOGY}

A survey was conducted on fifty-three persons who are interested in reading comics and have used other digital comic reader applications [21]. The method used was convenience sampling where survey was given to comic hobbyists and enthusiasts online. The list of questions that were asked in the survey are as following:

1. Do you think that physical comic books are getting more expensive nowadays?

2. Do you prefer to read comics on digital devices or printed books?

3. Assume you were an amateur artist; would you find it difficult to publish and promote your work to local readers?

4. Assume you were a comic artist; would you prefer to publish your work online or via printed media?

5. Do you think that lack of support for amateur artists is discouraging them from publishing their works?

Local comic book retailers were involved to provide feedback and opinion on the current implementation and proposed design of the comic reader application. Information that were synthesized and extracted from the survey was

- What is the preferred platform of current comic readers to obtain legal copies of comic books?

- What are the problems faced by local comic artists nowadays that the proposed application wants to tackle?

The data obtained from the survey was used to design ComicMart, a digital comic aggregator platform.

\section{RESULT}

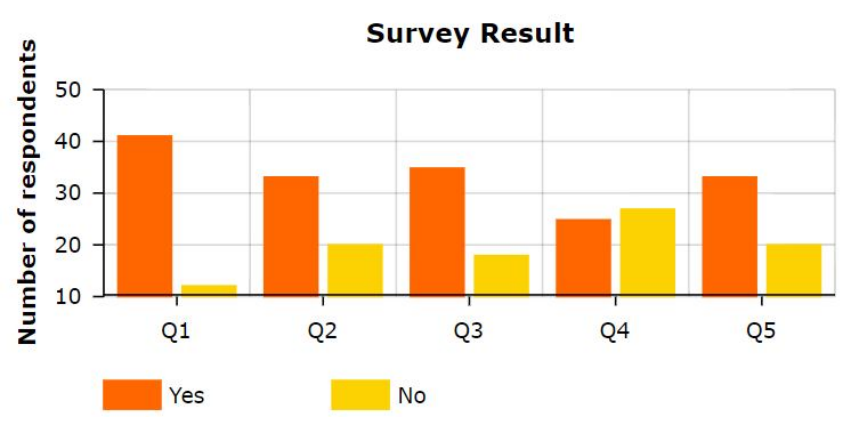

Figure 1: Bar chart of the respondent results 
Based on Figure 1, the answers of the respondent are turned into a clustered bar chart as visual representation of the data. According to the first question, the respondents were asked whether the printed comic books are getting more expensive than it used to be in the past. 41 out of 53 respondents or $77.3 \%$ have agreed whereas the remaining 12 respondents or $22.7 \%$ have disagreed to the statement. Based on the survey result, it can be concluded that the consumers have felt that physical comics books are getting expensive. Consumers no longer think that printed media is affordable and easy on the pocket [10].

Next, based on Question 2, the respondents were asked about their preferred media to consume comic books. 33 respondents or $62 \%$ have stated that they prefer reading comic books on digital devices, whereas the remaining 20 respondents or $38 \%$ have stated that they prefer printed books. This shows that the comic book consumers are gradually accepting digital medium as the new way to read comics [11]. However, there is still demand for physical comic books as $38 \%$ of respondents preferred printed media.

Based on Question 3, the respondents were asked that if they were an amateur artist, would they find it hard to publish their work and promote it to local readers. 35 respondents or $66 \%$ have agreed to the statement, whereas 18 respondents or $34 \%$ respondents have disagreed. From the data, it is clearly shown that there is a lack of platform for local artists to express and publish their works.

Based on Question 4, the respondents were asked that if they were a comic artist, would they choose to publish their work online or via printed media. 25 respondents or $47 \%$ have stated that they prefer to publish their work online, whereas 27 respondents have stated that they prefer physical media when it comes to publishing. It can be concluded that an average person would still prefer to publish their work in printed. However, nearly half of the sample population have voiced their preferences towards publishing on online platform.

Lastly, based on Question 5, the respondents were asked whether the lack of support for amateur artists is discouraging them from publishing their works. 33 respondents or $62 \%$ have agreed to the statement whereas the remaining 20 respondents or $38 \%$ have disagreed. More than half of the sample population thinks that the local artists in Malaysia are not getting the support they deserve. As a result, young artists could go unnoticed and will not get the recognition.
Types of comics consumed

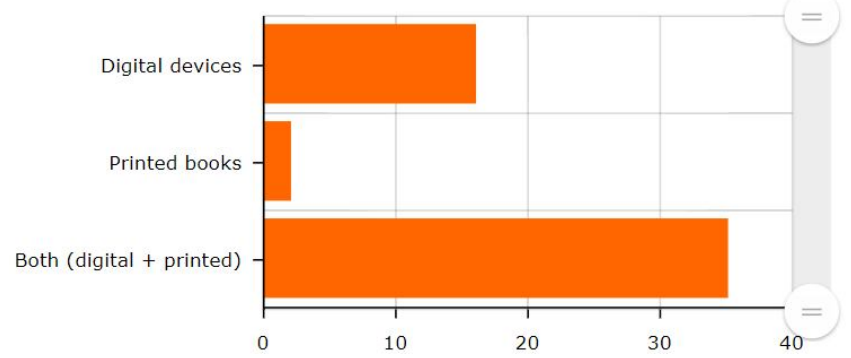

Figure 2: Types of comic books consumed according to respondents

Figure 2 shows the results for the types of comic books consumed by the respondents. 16 respondents or $30 \%$ have stated that they have only used digital medium to read comic books. On the other hand, only 2 respondents or $4 \%$ stated that they only read printed comic books. Lastly, 35 respondents or $66 \%$ have stated that they have used both mediums when it comes to reading comic books. From the data shown, it is clear that digital media is the most used medium for consuming comic books.

\section{CURRENT FRAMEWORK}

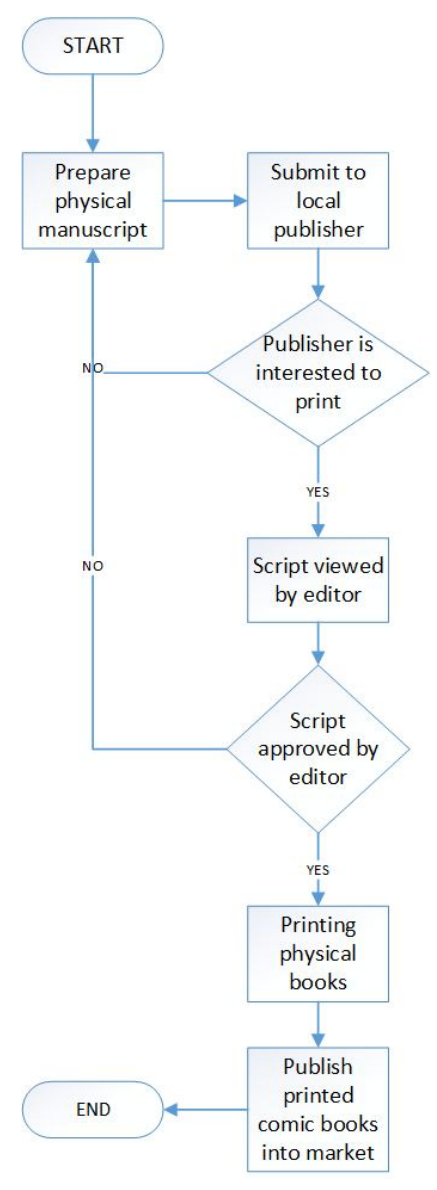

Figure 3: Current process of publishing printed comics via traditional method 
The current process of publishing printed comics as shown in Figure 3 is very lengthy and time-consuming. An average comic artist has to go through layers of processes in order to be able to publish their work in physical form [12]. First of all, a comic artist has to prepare either digital or physical manuscript as per requested by the publishing company. After submission, the publisher will review and make decision. If the publisher decides to publish his or her work, an editor will be assigned to review and edit the manuscript according to the company's interest. The artist will then make changes to the manuscript either willingly or unwillingly. Only after the lengthy process of reviewing and editing, the publisher will invest money to print the books. The whole process might take months from start to end and it is very taxing for an amateur artist [13].

\section{PROPOSED FRAMEWORK}

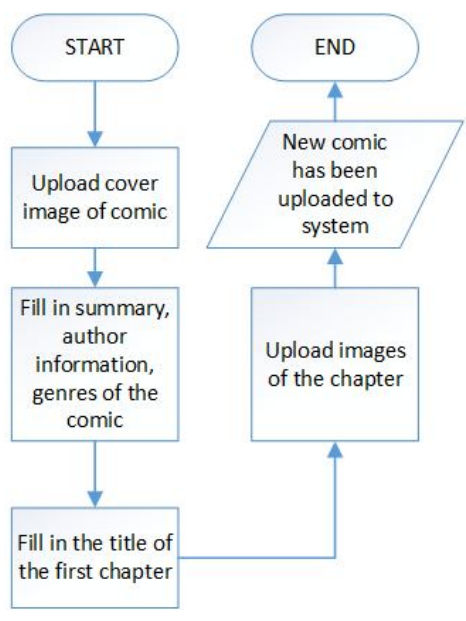

Figure 4: Process flow of publishing works to ComicMart

Figure 4 shows the process of publishing comics to ComicMart. By using the proposed platform, the long series of steps involved in Figure 3 (Printing books) could be skipped. There is no editor that will manage the script and it is all up to the artists' creativity to manage their works.

The artist first has to upload cover image for the comic. Afterwards, information of the comic such as summary, author nickname and genres have to be input into the system. Lastly, the artist needs to upload at least one chapter into the newly created comic series. After finishing all the steps, the comic will be visible to all users who visit the website.

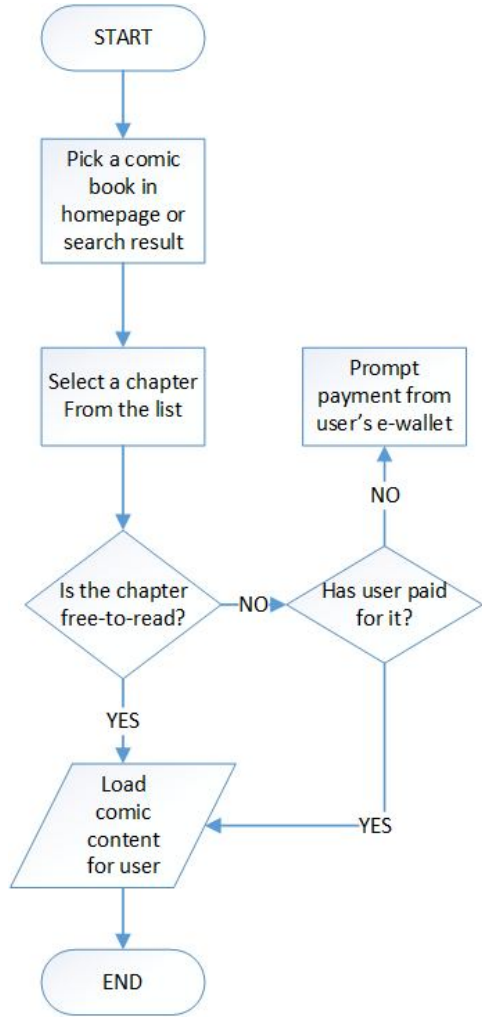

Figure 5: Process flow of reading comics in ComicMart

After the user has selected a comic book, it will then prompt the user to start reading from a chapter (usually first chapter). If the chapter belongs to premium category and has to be subscribed before reading, the system will check in database for entry whether the user has paid for it. If the user has not paid for it, the system will prompt the user to pay using the e-wallet functionality.

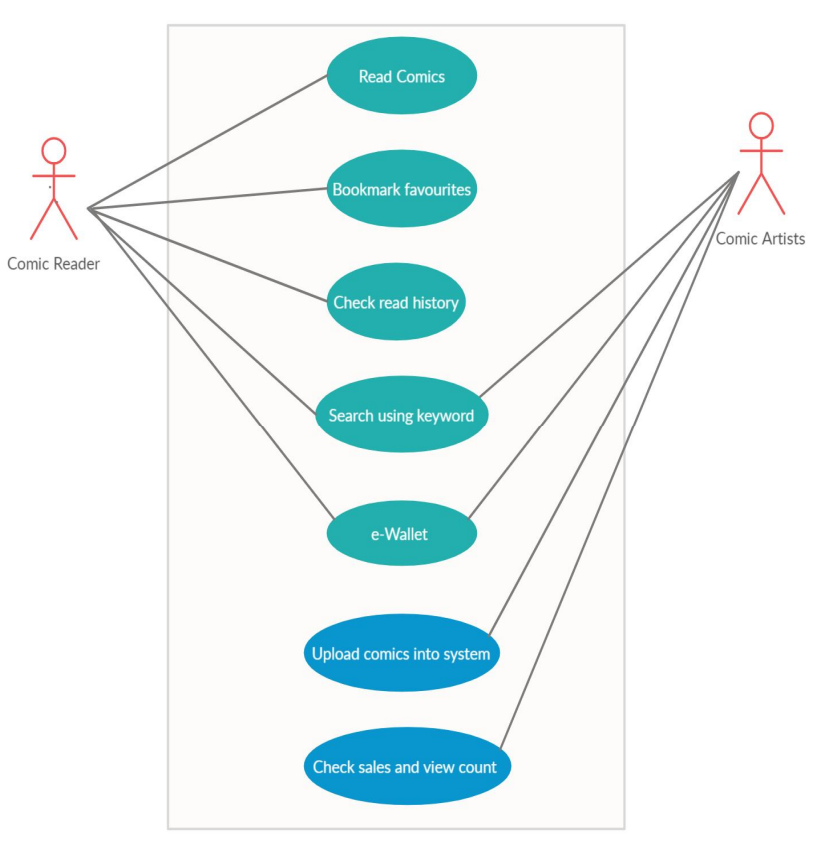

Figure 6: Use case diagram of ComicMart 
Figure 6 shows the use case for ComicMart. In the use case, there are two actors, namely Comic Reader and Comic Artists. There are 7 main activities in this use case diagram; read comics, bookmark favorites, check read history, search using keyword terms, e-Wallet functionality, upload comics into system and check sales \& view counts. Comic readers have access to read comics, bookmark favorites, check read history and e-Wallet functionality [5]. Meanwhile, comic artists have access to e-Wallet functionality, upload comics into system, check sales and view count functionality.

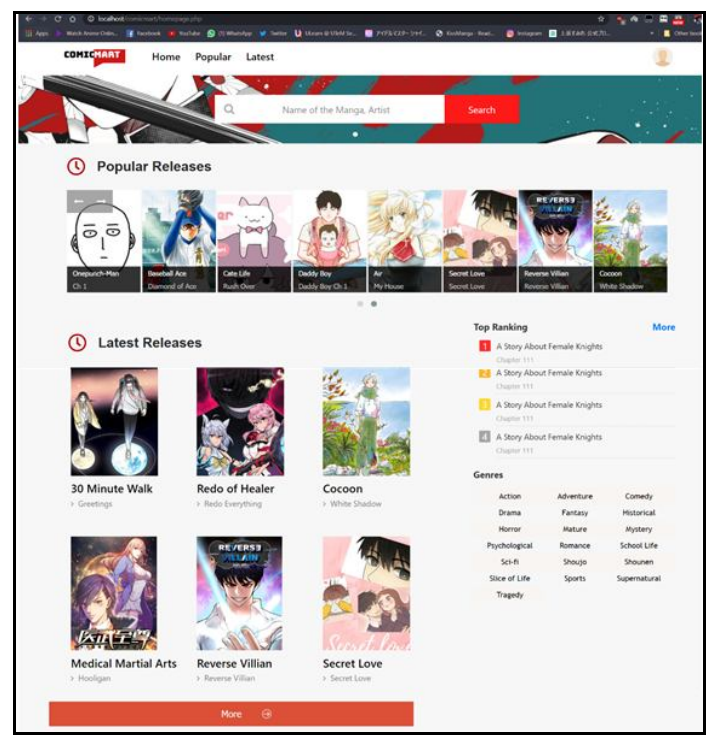

Figure 7: Home Page of ComicMart

Figure 7 shows the home page of the ComicMart. From the homepage, the user can type keyword into the search bar to look for similar or desired comic books. The homepage also shows the top ranked comic books according the view counts on the right-hand side. The center of the homepage contains list of recently uploaded or updated comic. The bottom right of the homepage also contains list of genres, which if clicked, will show the user all the comics with the selected genre.
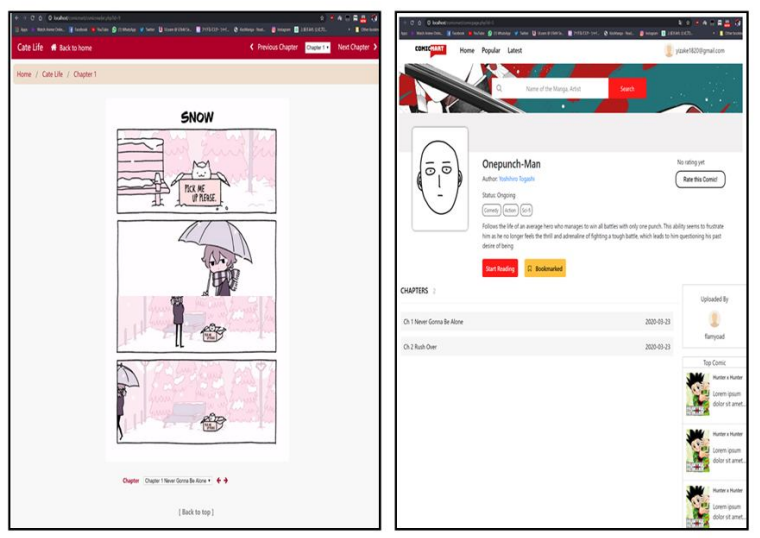

Figure 8: Reader module
Figure 8 shows the reader screen of the web application. The comic overview screen shows the information such as title, artist nickname, overall rating and the list of available chapters. It also contains bookmark button and a list of recommended comic books. The comic reader screen shows the comic strips in a vertical direction. It also contains a chapter selector where you can skip or go back to certain chapters.

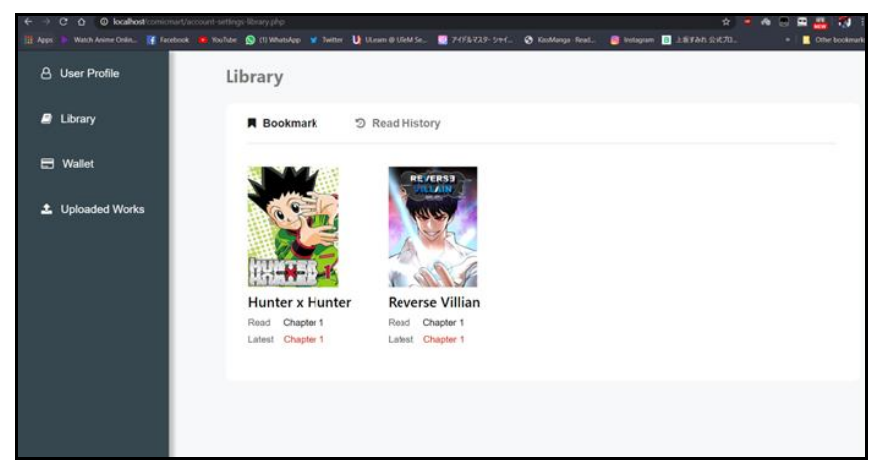

Figure 9: Bookmark \& Read History module

Figure 9 shows the screen of bookmark and read history functionality of the system. From the list of comics, you can check the last read chapter and the most updated chapter according to the database.
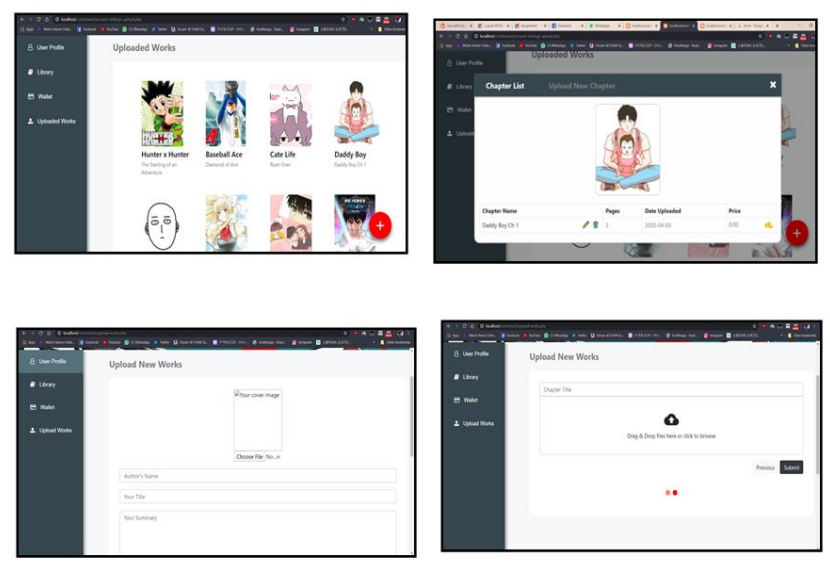

Figure 10: Comic uploader module

Figure 10 shows the comic uploader screen of the web application. The screen on upper left shows the list of uploaded comic series. The screen on upper right shows the list of chapters contained. The comic artist can choose to edit the title, price of the chapter or remove it from the list. The lower left shows the screen where you upload the cover photo and metadata of the comic such as genres and summary. The lower right shows the screen where you upload the chapter title and the images of the chapter. 


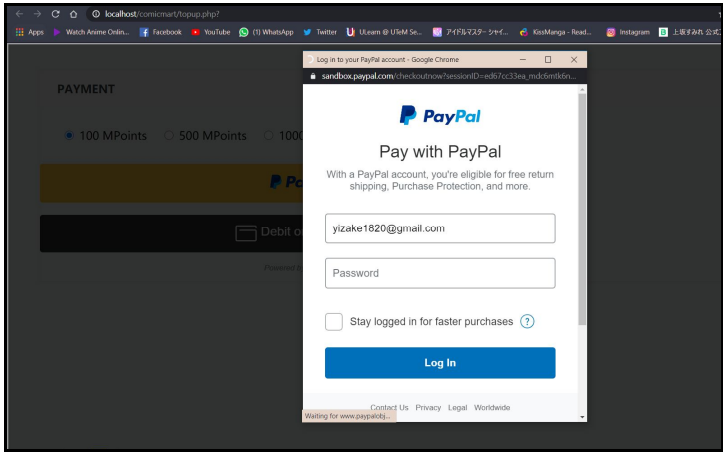

Figure 11: e-Wallet module

Figure 11 shows the screen of the e-Wallet module. In this system, PayPal API is used to implement the module. The user is required to sign up for PayPal account in order to gain access to premium content.

\section{CHALLENGES}

Reading digital comics is demanding now [14]. eBook readers and tablets have speed up the pace at which the digital comics is being adopted [15]. As digital industry gets larger, piracy should be an issue to worry about. Piracy rips creators' hard work and should not be taken lightly [16].

\section{FUTURE RESEARCH}

As modern technology keeps evolving to support the distribution of comics, major interactive features should be looked into consideration [17]. As opposed to static visuals, interactive comics are able to include rich multimedia elements such as video, audio, animation or accepting peripheral input like mouse click \& drag. Comic book could also be adopted in education sector [18].

\section{CONCLUSION}

This application can potentially solve a lot of grievances faced by local artists in Malaysia. This is especially true considering that a lot of young people nowadays draw, but they lack the incentive to monetize their works. By providing a platform for the young artists, it is hoped that local comic scene will be expanded. For end users, they are able to read the comics created by local people. If the work received a lot of good critics, the artist can consider charging premium subscription and earn money. This is aligned with the goal which is to provide a platform for artists to monetize their work like in YouTube.

\section{ACKNOWLEDGMENT}

This study was funded by Centre for Advanced Computing Technology (C-ACT), Universiti Teknikal Malaysia Melaka.

\section{REFERENCES}

1. Murray, Simone. The Digital Literary Sphere: Reading, Writing, and Selling Books in the Internet Era. JHU Press, 2018.

2. Aggleton, Jen. "Defining digital comics: a British Library perspective." Journal of Graphic Novels and Comics (2018). https://doi.org/10.1080/21504857.2018.1503189

3. Johnston, Hannah. "ComiXology and the Future of the Digital Comic Book." The iJournal: Graduate Student Journal of the Faculty of Information 2.2 (2017).

4. Kirchoff, Jeff. "Using Digital Comics to Develop Digital Literacy: Fostering Functionally, Critically, and Rhetorically Literate Students." Texas Journal of Literacy Education 5.2 (2017): 117-129.

5. Richardson, Eileen M. "Graphic Novels Are Real Books": Comparing Graphic Novels to Traditional Text Novels." Delta Kappa Gamma Bulletin 83.5 (2017): 24.

6. Tran, Tran, Thai, et al. "Monetization of digital content contributions." U.S. Patent No. 8,924,270. 30 Dec. 2014.

7. Ozuem, Wilson, Kerry E. Howell, and Geoff Lancaster. "The impact of digital books on marketing communications." Journal of Retailing and Consumer Services 50 (2019): 131-137.

8. Branscum, Paul, and Manoj Sharma. "Comic books an untapped medium for health promotion." American journal of health studies 24.4 (2009): 430-439.

9. Guérin, Clément, et al. "An ontology-based framework for the automated analysis and interpretation of comic books' images." Information sciences 378 (2017): 109-130. https://doi.org/10.1016/j.ins.2016.10.032

10. Kucirkova, Natalia. "An integrative framework for studying, designing and conceptualising interactivity in children's digital books." British Educational Research Journal 43.6 (2017): 1168-1185.

11. Wilde, Lukas. "Distinguishing mediality: The problem of identifying forms and features of digital comics." Networking Knowledge: Journal of the MeCCSA Postgraduate Network 8.4 (2015).

12. Skilton, Mark. Building the digital enterprise: a guide to constructing monetization models using digital technologies. Springer, 2016.

13. Kern, Adam. Manga from the floating world: comicbook culture and the kibyōshi of Edo Japan. Brill, 2019.

14. Arai, Kohei, and Herman Tolle. "Automatic e-comic content adaptation." International Journal of Ubiquitous Computing 1.1 (2010): 1-11.

15. Ponsard, Christophe, Ravi Ramdoyal, and Daniel Dziamski. An ocr-enabled digital comic books viewer." International Conference on Computers for Handicapped Persons. Springer, Berlin, Heidelberg, 2012. 
Ng Zhen Hao et al., International Journal of Advanced Trends in Computer Science and Engineering, 9(4), July - August 2020 , 6024 - 6030

16. Stevens, J. Richard, and Christopher Edward Bell. "Do fans own digital comic books? Examining the copyright and intellectual property attitudes of comic book fans." Piracy Cultures: How a Growing Portion of the Global Population Is Building Media Relationships Through Alternate Channels of Obtaining Content (2013).

17. Azman, Farah Nadia, Syamsul Bahrin Zaibon, and Norshuhada Shiratuddin. "Exploring digital comics as an edutainment tool: an overview." (2014): 589-594.

18. Steward, David, and Gale Horton Gay. "Comic Books Can Be More Than Entertainment." US Black Engineer and Information Technology 42.2 (2018): 48-50.

19. Z. Q. Shah, R. R. R. Ikram, S. Anawar, N. F. A. Yusof, and A. Idris, "Development of usability framework for projection mapping to increase food dining experience," International Journal of Advanced Trends in Computer Science and Engineering, vol. 9, no. 3, pp. 3150-3156, May 2020 doi: 10.30534/ijatcse/2020/102932020.

20. R. R. R. Ikram, et al., "A conceptual integrated health information systems framework in postnatal care for modern and traditional Malay medicine," Indonesian Journal of Electrical Engineering and Computer Science, vol. 17, no. 3, pp. 1531-1539, Mar. 2020, Accessed: Dec. 24, 2019. [Online]. Available: http://ijeecs.iaescore.com/index.php/IJEECS/article/vie w/20920/13541.

21. R. R. Raja Ikram, M. K. Abd Ghani, N. R. Ab Hamid, and L. Salahuddin, "Enabling Ehealth In Traditional Medicine: A Systematic Review Of Information Systems Integration Requirements," Journal of Engineering Science and Technology, vol. 13, no. 12, pp. 4193-4205, 2018, Accessed: Jan. 23, 2019. [Online]. Available: http://jestec.taylors.edu.my/Vol 13 issue 12 December 2018/13_12_22.pdf.

22. R. Alnanih, N. Bahatheg, M. Alamri, and R. Algizani, "Mobile-d approach-based persona for designing user interface," International Journal of Advanced Trends in Computer Science and Engineering, vol. 8, no. 5, pp. 2597-2607, 2019 doi: 10.30534/IJATCSE/2019/111852019.

23. Y. Thamilarasan and R. R. Raja Ikram, "MyMUET: A Design of a Mobile based Crowdsourced Assessment for Malaysia University English Test with Non-Synchronous Participant Interaction," International Journal of Innovative Technology and Exploring Engineering, vol. 8, no. 11, pp. 2971-2977, 2019, doi: 10.35940/ijitee. K2277.0981119. 